\title{
Good year, bad year: changing strategies, changing networks? A two-year study on seed acquisition in northern Cameroon
}

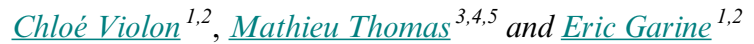

\begin{abstract}
Analysis of seed exchange networks at a single point in time may reify sporadic relations into apparently fixed and longlasting ones. In northern Cameroon, where environment is not only strongly seasonal but also shows unpredictable interannual variation, farmers' social networks are flexible from year to year. When adjusting their strategies, Tupuri farmers do not systematically solicit the same partners to acquire the desired propagules. Seed acquisitions documented during a single cropping season may thus not accurately reflect the underlying larger social network that can be mobilized at the local level. To test this hypothesis, we documented, at the outset of two cropping seasons (2010 and 2011), the relationships through which seeds were acquired by the members of 16 households in a Tupuri community. In 2011, farmers faced sudden failure of the rains and had to solicit distant relatives, highlighting their ability to quickly trigger specific social relations to acquire necessary seeding material. Observing the same set of individuals during two successive years and the seed sources they solicited in each year enabled us to discriminate repeated relations from sporadic ones. Although farmers did not acquire seeds from the same individuals from one year to the next, they relied on quite similar relational categories of people. However, the worse weather conditions during the second year led to (1) a shift from red sorghum seeds to pearl millet seeds, (2) a geographical extension of the network, and (3) an increased participation of women in seed acquisitions. In critical situations, women mobilized their own kin almost exclusively. We suggest that studying the seed acquisition network over a single year provides a misrepresentation of the underlying social network. Depending on the difficulties farmers face, they may occasionally call on relationships that transcend the local relationships used each year.
\end{abstract}

Key Words: agrobiodiversity; climate variability; gender; kinship relationships; longitudinal network analysis; seed exchange networks

\section{INTRODUCTION}

Studies on seed exchange networks are usually based on data collected at a specific moment in time. Often implicit in these analyses is the assumption that such instances are representative of structurally unchanging networks. Networks, however, are the result of cumulated actions of a varied set of actors and are dynamic through space and time (Pautasso et al. 2013).

Researchers interested in networks in farming communities have relied on synchronic approaches, whether their studies concern the investigation of local ecological knowledge and expertise (Atran et al. 2002, Isaac et al. 2007) or more recently, seed exchanges (Abay et al. 2011, Calvet-Mir et al. 2012, Kawa et al. 2013, Reyes-Garcia et al. 2013). Such networks are established either through snapshot surveys of transactions at a given time or through the assessment of all the exchanges that occurred along the life span of individuals without taking into account their dynamic processes. In many peasant communities, seed networks do not proceed from permanent institutions but rather emerge as the result of exchanges within pre-existing social relationships between individual farmers (Badstue et al. 2006, Leclerc and Coppens d'Eeckenbrugge 2012). Describing seed exchange networks through snapshot data on seed transactions may reify sporadic relations into putatively long-lasting ones (Poudel et al. 2015). The risk is that these data will be used to deduce structural norms about which relationships are preferred, even though the relationships observed may only be contingent upon conditions of the period studied.

Moreover, when seed exchanges are studied in settings where environmental unpredictability is high, a longitudinal approach to network analyses is more relevant. Case studies have pointed to the effects of climatic hazards confronting seed exchange networks (Bellon et al. 2011, McGuire and Sperling 2013). Growing uncertainty about climate among farmers, as is the case in the Sudano-Sahelian region, directly impacts farmers' adaptation strategies (Eldin and Milleville 1989, Crane et al. 2011). Securing access to seeds is one component of these strategies.

From a diachronic case study on seed acquisitions, documented successively for two annual cropping cycles with contrasting patterns of rainfall in a farming community in northern Cameroon, our endeavor was to understand to what extent climatic variability influences the transaction patterns within the same seed system. Because getting the right seeds at the right time is a key issue, we argue that climatic hazards significantly affect the mechanisms underlying seed exchanges. We particularly wanted to better understand the extent to which a rainfall anomaly during the cropping season impacts the choice of (1) acquired crop species and landraces and (2) seed providers. As working hypotheses we assumed that, to cope with unpredictable climate conditions, farmers tend to focus their seed-provisioning efforts on major crops (i.e., cereals), seeking to diversify their landrace portfolios (McGuire and Sperling 2013), and that they mainly rely on seed sources from within their community (Bellon et al. 2011), and particularly on kinship ties of male household heads (Delêtre et al. 2011).

\section{Study context}

The study was conducted in the Tupuri area, located in the Southern Diamaré floodplains of the far-north region of

${ }^{1}$ Université Paris Ouest, ${ }^{2}$ Laboratoire d'Ethnologie et de Sociologie Comparative (LESC - UMR 7186), ${ }^{3}$ INRA, UMR 0320 / UMR 8120 Génétique Quantitative et Évolution - Le Moulon, ${ }^{4}$ CNRS, Centre d'Écologie Fonctionnelle et Évolutive: UMR 5175, ${ }^{5}$ CESAB/FRB 
Cameroon. Several villages, rarely located further than $5 \mathrm{~km}$ from the closest neighboring village, are subdivided into administrative neighborhoods (Kolyang 2010).

The study was carried out with 16 households from 3 neighborhoods (including 21, 49, and 52 households, respectively) in two adjoining villages (1 neighborhood in Lokoro and 2 neighborhoods in Gulurgu) whose combined population reaches approximately 2000 inhabitants. As illustrated in Figure 1, a household is usually composed of a man, his wife or wives (polygyny is widespread), and all of their unmarried children. Descent is patrilineal and residence is patrilocal. Upon marrying, a young man often builds his new homestead in the vicinity of his father. A newlywed woman moves from her native village to her husband's residence (Ruelland 1983). However, within a neighborhood, different patrilineal kin groups may be present, and people without any kinship ties may cohabit as neighbors or friends (Fig. 1).

Fig. 1. Illustration of the main social relationships between seed givers and recipients. The focal recipient A is in black. The shaded area represents the neighborhood area. Households are defined by a black circle. Males are represented by triangles and females by circles. Thin black lines represent genealogical relations. Seed diffusion among relatives is represented with thick-line arrows with in-laws in brown (e.g., B-A and C-A), uterines in green (e.g., D-A), and agnates in blue (E-A). Seed diffusion among nonrelatives is represented using dashed-line arrows with neighbors in black (e.g., F-A), friends in dark grey (e.g., G-A) and acquaintances or strangers in light grey (H-A).

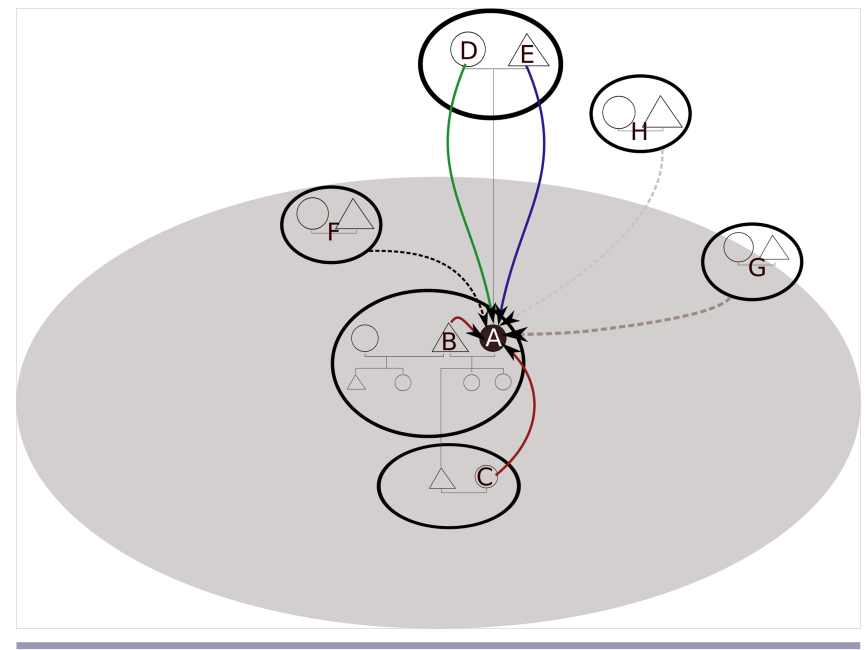

Because of the exogamic rule, often leading men to seek marriageable women outside their village, Tupuri farmers are accustomed to transactions of goods as much outside their village as inside (C. Violon, unpublished data). Gift transactions are the most numerous but are, in most cases, initiated by recipients who express to a targeted provider their desire to acquire what they need. Moreover, transactions involving money are not restricted to market places and can occur on a daily basis in fields or at home, between neighbors, friends, or even close kin (Violon and Wencélius 2014). Consequently, within this local community, and notably for seeds, there is no unique transaction system, but multiple ways of transferring goods from farmer to farmer.
Although cattle are an important means of capitalization and are highly valued for their symbolic and social significance, Tupuri farmers rely for their subsistence mostly on agriculture and the collection of wild vegetables. Fishing and hunting are minor practices.

The Tupuri farming system is organized into three distinct agroecological zones. The first one consists of the home plots surrounding the dwellings where rain-fed red sorghum, the major staple, is grown. Red sorghum includes a large diversity of cultivars (nearly 30 ) and has a high culinary and social value (Garine et al. 2013). Farmers dedicate most of their energy and their best plots to this cereal. A small area, less than $25 \%$ of the area, is often devoted to the sowing of a few panicles of pearl millet and of maize, two other cereals from which women can prepare daily meals. Many other secondary crops, mostly legumes and greens, are also grown and are mainly used to prepare relishes. These fields are inherited through patrilineal descent, and their size may vary from household to household. The second zone, bush fields, is more remote from households and soils there are sandy. A greater diversity of crops is grown in these fields: large areas (4.2 acres in average) are sown with pearl millet, cassava, cowpea, peanut, and some secondary crops. Such fields are not privately owned; thus farmers in theory can cultivate as many plots as they can each year. The last zone corresponds to floodprone areas, which are much appreciated for off-season crops. These lands, recently cleared, are mostly devoted to a high diversity of cultivars of transplanted sorghum (Garine et al. 2013), which provide supplementary cereal grain production during the dry season (Raimond 1999, Seignobos 2000). Consequently, selling and renting of these plots are increasingly frequent.

Two main crop categories stand out: (1) the major crops, including the above-mentioned cereals used for daily meals and other important crops of the agrosystem grown on large areas and by numerous farmers, such as cassava, peanut, or cowpea; and (2) the minor or secondary crops, comprising all other species cultivated in smaller quantities (e.g., sorrel, okra, sesame) or by fewer farmers (e.g., tobacco, sweet potato, rice).

Throughout a farming season, farmers always devote most of their time to their home plots. Each household's home plot is divided equally among the wives, each one working her share with her own children. After sowing and first weeding, any farmer, whether a woman, a household head, or an adolescent, who desires to grow other plots then undertakes the clearing and management of their own bush fields from July to August. At the end of the rainy season, when the flood is about to recede, adults clear the flood-prone fields while carrying out the last weeding in the bush fields. Harvests take place from October (rain-fed sorghum) to March (transplanted sorghum).

Agricultural activity is therefore concentrated during the short rainy season and the beginning of the dry season. During most of the dry season, farmers allocate their time to other activities, i.e., construction, wage labor, and ritual ceremonies.

Although the seasonality of rainfall is strongly unimodal, with a rainy and a dry season,, intra-annual and interannual rainfall (Fig. 2a) may vary quite differently from year to year. Our study covers both what can be considered, according to local discourse, 
a "good year" (2010) and a "bad year" (2011). In 2011, the total amount of rainfall was only slightly below average $(847 \mathrm{~mm}$ in 2011 vs. $1084 \mathrm{~mm}$ in 2010 and an average of $854.75 \mathrm{~mm}$ for the period 1990-2011). However, it was considered a bad year by farmers because the onset of rainfall was late, starting only in July (nearly two months after the usual beginning of the rainy season, at the end of May: Fig. 2b). This anomaly necessitated, for all farmers, a sudden replanning of their cropping strategy.

Fig. 2. Precipitation in Dukula, the main village of the district. a) Precipitation between 1990-2011. For this period, the mean annual precipitation was $854.75 \mathrm{~mm}$ (standard deviation 163 $\mathrm{mm}$ ). b) Precipitation during the rainy seasons in 2010 (in grey) and 2011 (in black). Source: SODECOTON, Maroua, North Cameroon (unpublished data).

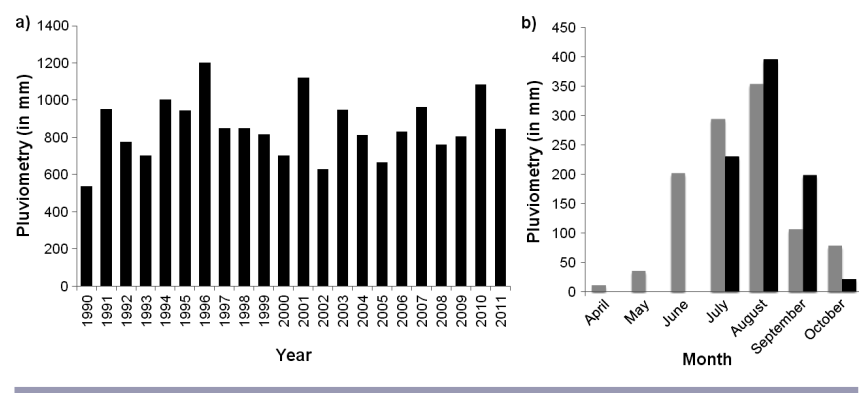

\section{METHODS}

Both ethnographic observations and systematic surveys were carried out in our study. These methods enabled us to combine qualitative and statistical analyses.

\section{Data collection}

We worked in 16 households and interviewed 63 farmers: 16 household heads, 30 wives and mothers, and 17 adolescents aged 15-20 years, the latter usually growing their own cash crops. Households were selected to represent a 3-level gradient of economic wealth (poor, intermediate, rich) to test for variations in strategies in seed acquisition. We selected 5 poor households, mostly widows or old people; 6 intermediate households, young couples starting their agricultural career; and 5 rich households, generally a man and two or more wives and their children and possessing an ox plough, cattle. and large areas of land.

To describe seed acquisition patterns, fieldwork was conducted during two different periods: from January to March 2011 (dry season after the good year: 2010) and from August to October 2011 (wet season, during the bad year). For each cropping season, interviews were carried out with the same set of farmers to document all seed acquisition events for each species and landrace. Our main question was, "Who gave you seeds from this landrace last cropping season?" Our data collection covered all types of propagules, whatever the type of species (i.e., true botanical seeds for sexually reproduced species or cuttings or tubers for clonally reproduced plants) and whatever use they were put to (first or second sowing; small or large quantities).

Whatever their status in the family, our 63 informants were interviewed following the same questions on their seed acquisitions for the two years. For the 2010 cropping season, interviews were conducted in January, six months after events had occurred. Consequently, farmers were asked, at home, to mention the seed source for every crop they said they had sown in each of their plots; inventories were made of the production stocked in granaries. For the 2011 cropping season, data were gathered through repeated inquiries (every two weeks) on the most recent source of seeds for each species and landrace in every plot under cultivation. The main difference between the 2010 and the 2011 protocols lay in the way the crop inventory was generated: examining seed stores in the granaries in January or conducting direct observations in the fields in August. Questions relating to seed acquisitions were the same in the two periods. Because conducting interviews with all members of each household minimized the risk of omissions (Wencélius et al. 2016), we believe the thoroughness of our 2010 protocol enabled us to limit any potential bias, such as omissions of some secondary crops or landraces, resulting from generating a post hoc inventory of plants grown.

Each event corresponds to the acquisition of seeds by an informant recipient from a mentioned provider, who may or may not have been interviewed, for a particular cropping season (2010 or 2011). Additional information was collected to document these events: name, household membership, gender and age of both providers and recipients, the social relationships between provider and recipient, date and location of event, means of acquisition, and quantities of seeds acquired.

\section{Data analysis}

All the statistical analyses and representations were performed using the stats and ade4 packages (Dray and Dufour 2007) in R version 3.1.2 software (R Development Core Team 2014).

\section{Data transformation}

The information gathered to document each seed acquisition was transformed into nominal variables, when this was not already the case, to fit statistical requirements. For instance, quantities were measured in "cups," which is the standard measure in local markets for food and grain. A cup amounts to approximately 200 grams of sorghum grain. The data were then converted into 3 categories: under 1 cup, 1-2 cups, and more than 2 cups. For geographical information, 5 classes were created based on a calculation of the distances between residences of providers and recipients, based on an extensive GPS survey of household locations (for recipients and providers from the study site) or village of residence (for providers from outside the studied community).

The event variable capturing social relationships between recipient and provider was defined based on our understanding of local social interactions, the collection of genealogical data (2605 individuals) at the community level, and careful ethnographic description of emically meaningful categories of social relationships. Two partners were considered as kin-related (agnates or patrilineal kin, uterines or matrilineal kin, in-laws) whenever a kinship relation was acknowledged between them, whatever the degree. Friendship was defined as such by informants (bàr.bë in Tupuri language). A neighbor is a member of the same village with whom no kin or friendship relationship exists. An acquaintance is a person whom informants know from another village but with whom the informant has had no frequent interactions. A stranger is a person whom the informant did not know before the transaction (Fig. 1). The category "others" covers 
relationships established through more formal channels, i.e., employees from the state-governed cotton corporation.

To summarize, 8 variables were selected to characterize each seed acquisition event. First, we consider the cropping season (2010 or 2011) as the main variable. Second, 2 individual attributes were taken into account: gender of the recipient (male or female) and economic status of his/her household (poor, intermediate, rich). Thirdly, 5 additional variables helped to qualify the acquisition events: categories of acquired crops ( 2 modalities: major or secondary); quantities acquired (under 1, 1-2, more than 2 cups); origin of seed sources (within household, within neighborhood, within village, or outside village); geographical distance between provider and recipient (less than 1, 1-3, 3-5, 5-10, or more than $10 \mathrm{~km}$ ); and social relations between transacting partners (uterines, agnates, in-laws, neighbors, friends, acquaintances, strangers, others).

\section{Network representation}

As the number of seed acquisition events per year and per farmer was limited, we chose to represent seed acquisition networks at the household level; i.e., each node corresponds to a household. Networks are directed; i.e., each directed link corresponds to an acquisition event from a seed provider to a seed recipient (interviewed). Networks were analyzed using igraph version 0.6.6 1. (Csardi and Nepusz 2006), a package developed in R.

\section{Statistical analyses}

We performed a multiple correspondence analysis (MCA) to obtain a descriptive representation of the data set. MCA is a multivariate analysis equivalent to principal component analysis but adapted for categorical variables (Tenenhaus and Young 1985). Each point is an acquisition event that is described by the eight above-mentioned variables. The multidimensional space in which seed acquisition events were plotted is summarized in a two-dimensional projection using the two first principal components of the spectral decomposition. To interpret this projection and the contribution of each variable to the positioning of the points, one plot was drawn for each variable and the points colored in accordance to the category they fell into for the variable under consideration.

Because our objective was to detect differences in terms of seed acquisition behaviors between two cropping seasons, Pearson's chi-squared tests were performed between the cropping season variable and each of the seven other above-mentioned variables. This procedure tested the null hypothesis that distribution of occurrences among the categories of a given variable is statistically independent of the cropping season. We reject the null hypothesis, when $\mathrm{p}<0.05$ for a critical threshold $\alpha=5 \%$, because it indicates that distribution of occurrences is dependent on the cropping season. Our results need to be interpreted with caution because, for a robust use of this test, observations should be independent, which is not entirely the case in our study context and because of the sampling method. Seed acquisitions by one household member are contingent on other seed acquisitions within the same household. Even if each member of a household has his/her own fields, they help each other during land clearing or weeding and also in seed management. For sorghum in particular, several members can be involved in different seed acquisition events to have sufficient seeds to sow the same field. However, each individual farmer, including women and youngsters, also have the liberty to develop their own cropping strategy, including seed acquisitions, for personal plots. Nevertheless, the chi-squared test is the most reasonable statistical method for such open and sparse networks. Moreover, interviewing 16 households chosen to obtain equal sampling of three socioeconomic groups (and thereby to test the social inequality hypothesis) introduces a bias because it leads to overrepresentation of rich households in our sample.

\section{RESULTS}

In all, 305 seed acquisition events were recorded: recipients were women in 197 cases and men in the remaining 108, and these events were not randomly distributed between the 2 years. Household strategies to acquire seeds during the bad year were significantly different from those during the good year $(\mathrm{p}=0.050)$. This finding was confirmed by the aggregate network of seed acquisitions (Fig. 3), which indicates (1) a greater number of seed acquisitions in 2011 (177 events, compared with 128 in 2010) and (2) a small number of repeated transactions in 2010 and 2011 between the same pairs of households (grey ties in the figure). The mean number of seed acquisition events per household was also higher in 2011 (mean = 11.1 acquisitions per household; standard deviation $[\mathrm{SD}]=6.2)$ than in 2010 (mean $=8.0$ acquisitions per household; $\mathrm{SD}=3.9$ ).

Fig. 3. The aggregate network of seed acquisitions for the two cropping seasons. Interviewed households are nodes in green, and providers not interviewed are nodes in blue. The colors of the edges represent the year of the seed acquisitions (blue for 2010, red for 2011, grey if the transaction occurred both years). Loops represent seed acquisitions within the household i.e., from one household member to another. The width of an edge represents the number of observed events between pairs of nodes (ranging from 1 to 13 ). The density of this unidirectional network is 0.014 .

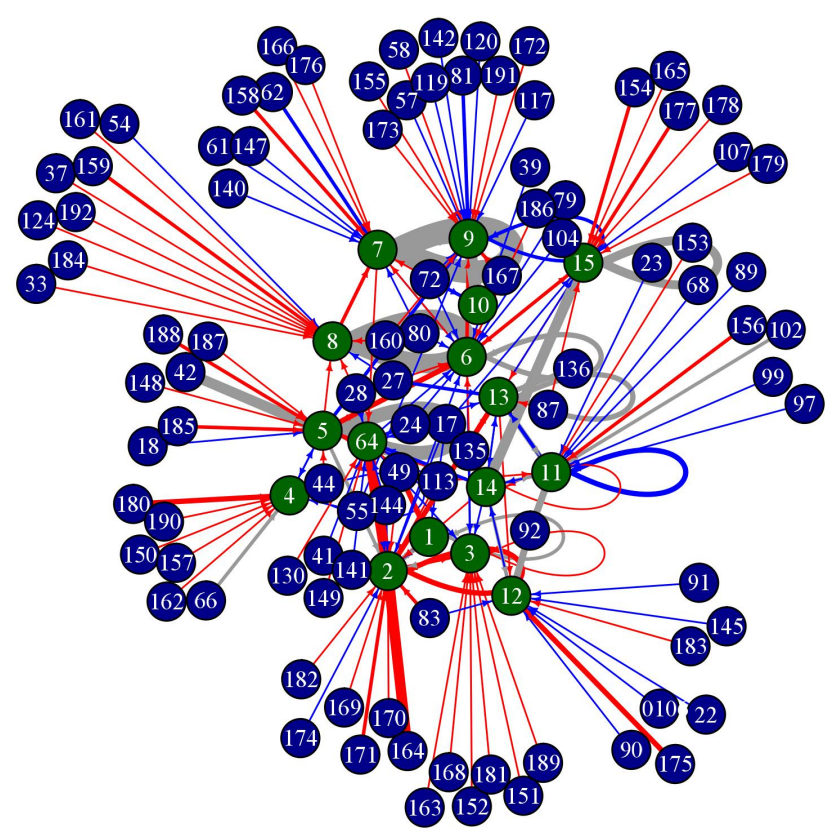


Table 1. Distribution of seed acquisition events (observed and expected values) according to the seven variables and the two cropping seasons and results of Pearson's chi-squared tests. Tests were considered significant $(*)$ when $\mathrm{p}<0.05$.

\begin{tabular}{|c|c|c|c|c|}
\hline & & $\begin{array}{c}\text { Values } \\
\text { observed and (expected) } \\
2010\end{array}$ & $\begin{array}{c}\text { Values } \\
\text { observed and (expected) } \\
2011\end{array}$ & $\mathrm{p}$ value \\
\hline \multirow[t]{3}{*}{ Gender of the recipient } & & & & $0.003^{*}$ \\
\hline & Male & $58(45)$ & $50(63)$ & \\
\hline & Female & $70(83)$ & $127(114)$ & \\
\hline \multirow[t]{4}{*}{ Economic status of the household } & & & & 0.104 \\
\hline & Poor & $38(31)$ & $35(42)$ & \\
\hline & Intermediate & $45(52)$ & $78(71)$ & \\
\hline & Rich & $45(46)$ & $64(63)$ & \\
\hline \multirow[t]{3}{*}{ Categories of acquired crops } & & & & 0.200 \\
\hline & Major crops & $86(80)$ & $105(111)$ & \\
\hline & Minor crops & $42(48)$ & $72(66)$ & \\
\hline \multirow[t]{4}{*}{ Quantities acquired } & & & & 0.304 \\
\hline & $<1$ cup & $58(54)$ & $70(74)$ & \\
\hline & $1-2$ cups & $41(47)$ & $72(66)$ & \\
\hline & $>2$ cups & $29(27)$ & $35(37)$ & \\
\hline \multirow[t]{5}{*}{ Origin of seed sources } & & & & 0.069 \\
\hline & Household & $26(24)$ & $30(32)$ & \\
\hline & District & 57 (49) & $59(67)$ & \\
\hline & Village & $13(13)$ & $17(17)$ & \\
\hline & Outside & $32(43)$ & $71(60)$ & \\
\hline \multicolumn{2}{|c|}{ Geographical distance between provider and recipient } & & & $0.003 *$ \\
\hline & $<1 \mathrm{~km}$ & $95(81)$ & $99(113)$ & \\
\hline & $1-3 \mathrm{~km}$ & $13(15)$ & $22(20)$ & \\
\hline & $3-5 \mathrm{~km}$ & $9(10)$ & $15(14)$ & \\
\hline & $5-10 \mathrm{~km}$ & $5(5)$ & $7(7)$ & \\
\hline & $>10 \mathrm{~km}$ & $6(17)$ & $34(23)$ & \\
\hline \multicolumn{2}{|c|}{ Social relationships between transacting partners } & & & 0.095 \\
\hline & Agnate & $19(13)$ & $12(18)$ & \\
\hline & In-law & $29(36)$ & $57(50)$ & \\
\hline & Friend & $18(15)$ & $17(20)$ & \\
\hline & Acquaintance & $12(11)$ & $15(16)$ & \\
\hline & Stranger & $2(7)$ & $14(9)$ & \\
\hline & Uterine & $14(21)$ & $35(28)$ & \\
\hline & Neighbor & $33(25)$ & $27(35)$ & \\
\hline & Other & $1(0)$ & $0(1)$ & \\
\hline
\end{tabular}

The increase in transactions during the second year was associated with a slightly greater number of providers (74 providing households in 2011 vs. 62 in 2010). Substantial differences were also noted as to quantities, across all species and landraces: in 2010 acquisitions totaled 280 cups, whereas 411 cups of seeds were acquired in 2011.

More substantial differences between the two years in terms of farmers' strategies were observed when we examined the distribution of events, variable by variable. In the following section, we describe seed transaction behaviors based on the results obtained through chi-squared tests (Table 1) and the MCA (Fig. 4).

\section{A trend to diversifying the seeding material}

Contrary to our expectations, farmers did not focus their efforts exclusively on acquiring seeds of major crops during the bad year of 2011 because no significant changes were observed in terms of crop categories between the two cropping seasons $(p=0.200$; Table 1). Farmers actually maintained the diversity of cultivated species by seeking seeds of secondary crops such as okra, sorrel, and watermelon. The recorded predominance of major crops in the 2010 seed acquisitions (86 events [67.2\%] vs. 42 [32.8\%] for secondary crops; Table 2) was in fact less substantial in 2011, because of a greater proportion of seed transactions involving secondary crops (105 events [59.3\%] for major crops vs. 72 [40.7\%] for secondary crops; Table 2). Ethnographical observations also pointed to an increase of biological diversity, because seed transactions for some secondary species such as sweet potato, eggplant, cucumber, and rice were conducted only in 2011.

Nevertheless, when we examined at a finer scale the data within these crop categories, some changes were observed in the species or landraces acquired, particularly within the cereal group (Table 2). In both years, red sorghum, the most extensively grown and valued crop, was the crop for which seeds were most frequently transacted: $28.9 \%$ and $24.3 \%$ of all seed acquisitions in 2010 and 2011, respectively. Acquisitions of other categories of sorghum, e.g., late red sorghum, early and late transplanted sorghum, either decreased or disappeared during the bad year. The major shift in cereal choice, in 2011, concerned pearl millet seeds, which farmers sought to acquire more often. In fact, from 2010 to 2011, pearl millet registered the largest increase in seed acquisitions (three events in 2010 vs. 21 in 2011). Although no particular adjustment between the two years appeared when large categories of crops were considered, variations in acquisition patterns were observed 
Fig. 4. Multiple correspondence analysis on the 305 circulation events. a) Cropping season: good year (2010) in blue and bad year (2011) in red. b) Gender of the recipient: female in blue, male in red. c) Economic status of the household: poor households in blue, intermediate households in red, and rich households in green. d) Categories of acquired crops: major crops in red and secondary crops in blue. e) Quantities acquired: less than one cup in blue, between one and two cups in red, and more than two cups in green. f) Origin of seed sources: within the same household in red, within the same district in blue, within the same village in grey, and from outside the same village in green. g) Geographical distance between provider and recipient: less than one kilometer in green, from one to three kilometers in grey, from three to five kilometers in dark red, from five to 10 kilometers in blue, and more than 10 kilometers in red. h) Social relationships between transacting partners: agnates in light red, uterines in light grey, in-laws in dark grey, friends in green, neighbors in dark red, acquaintances in blue, strangers in black, and others in purple. Ellipses contain $63 \%$ of the points per category.
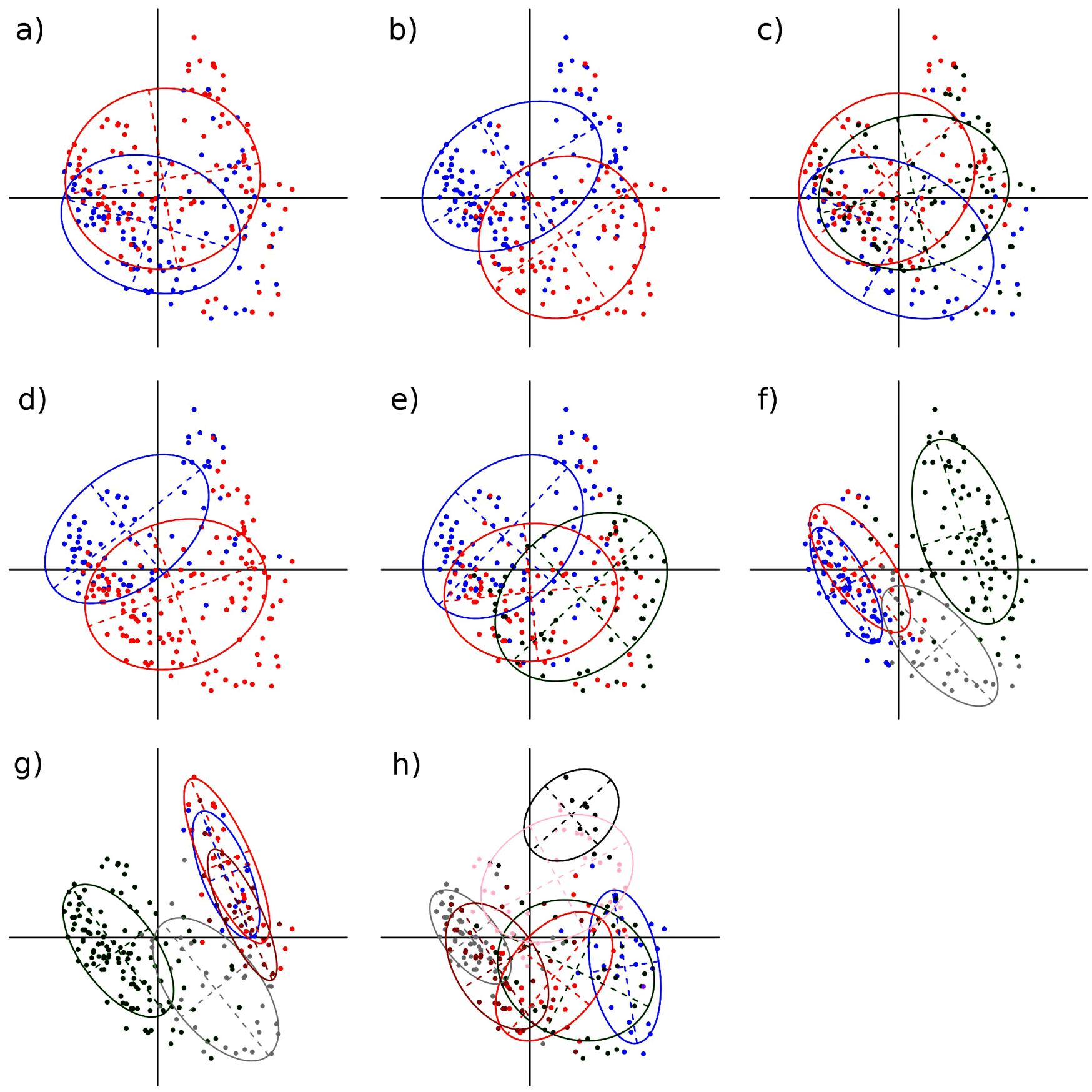
Table 2. Seed acquisition events according to crop categories and species for 2010 and 2011.

\begin{tabular}{|c|c|c|c|}
\hline & & 2010 & 2011 \\
\hline \multicolumn{2}{|c|}{ Major crops } & 86 & 105 \\
\hline & Red sorghum (Sorghum bicolor [L.] Moench) & 37 & 43 \\
\hline & Pearl millet (Pennisetum glaucum [L.] R. Br) & 3 & 21 \\
\hline & $\begin{array}{l}\text { Late transplanted sorghum (Sorghum bicolor } \\
\text { [L.] Moench) }\end{array}$ & 11 & 10 \\
\hline & Cowpea (Vigna unguiculata [L.] Walp.) & 8 & 9 \\
\hline & $\begin{array}{l}\text { Bambara groundnut (Vigna subterranea }[\mathrm{L} .] \\
\text { Verdc.) }\end{array}$ & 7 & 7 \\
\hline & Peanut (Arachis hypogaea [L.] 1753) & 11 & 7 \\
\hline & Cassava (Manihot esculenta Crantz) & 2 & 5 \\
\hline & Maize (Zea mays [L.] 1753) & 2 & 3 \\
\hline & $\begin{array}{l}\text { Early transplanted sorghum (Sorghum bicolor } \\
\text { [L.] Moench) }\end{array}$ & 2 & 0 \\
\hline & $\begin{array}{l}\text { Late red sorghum (Sorghum bicolor }[\text { L.] } \\
\text { Moench) }\end{array}$ & 3 & 0 \\
\hline \multicolumn{2}{|c|}{ Minor crops } & 42 & 72 \\
\hline & Sorrel (Hibiscus sabdariffa [L.] 1753) & 9 & 18 \\
\hline & Okra (Hibiscus esculentus [L.]Moench, 1794) & 4 & 15 \\
\hline & $\begin{array}{l}\text { Calabash (Lagenaria siceraria [Molina] Standl., } \\
\text { 1930) }\end{array}$ & 5 & 9 \\
\hline & $\begin{array}{l}\text { Watermelon (Cucurbita maxima Duchesne, } \\
\text { 1786) }\end{array}$ & 4 & 6 \\
\hline & $\begin{array}{l}\text { Black sesame (Sesamum radiatum Schumach. } \\
\text { and Thonn.) }\end{array}$ & 3 & 4 \\
\hline & False sesame (Ceratotheca sesamoides Endl.) & 1 & 3 \\
\hline & Kenaf (Hibiscus cannabinus L., 1753) & 2 & 3 \\
\hline & Sesame (Sesamum indicum L., 1753) & 4 & 3 \\
\hline & Eggplant (Solanum aethiopicum L., 1756) & 0 & 3 \\
\hline & Pepper (Capsicum spp. L., 1753) & 3 & 2 \\
\hline & Sweet potato (Ipomoea batatas [L.] Lam., 1793) & 0 & 2 \\
\hline & Cucumber (Cucumis sativus L., 1753) & 0 & 2 \\
\hline & Tobacco (Nicotiana tabacum L., 1753) & 6 & 1 \\
\hline & Rice (Oryza sativa L., 1753) & 0 & 1 \\
\hline & Molokhia (Corchorus olitorius L.) & 1 & 0 \\
\hline \multicolumn{2}{|r|}{ 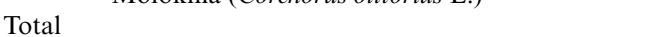 } & 128 & 177 \\
\hline
\end{tabular}

when particular species and groups of landraces were considered. The marked increase in pearl millet acquisitions led us to investigate how and where farmers gain access to acquire seeds to meet a sudden growing demand.

\section{A geographical expansion of the network}

Our study of the social network variability from year to year shows an important variation in the geographical patterns of seed acquisitions. From 2010 to 2011, significant changes were observed (Table 1) for geographical distance of seed transactions $(p=0.003)$ and to a lesser extent, for the origins of seed sources $(\mathrm{p}=0.069)$.

Whereas in 2010, farmers mostly sought seeds within the village and its immediate surroundings $(75 \%$ of seeds were acquired through persons living within a $5 \mathrm{~km}$ radius from the study site of Lokoro; Fig. 5a), in 2011 they acquired seeds further away (Fig. $5 b)$. During the second year, the majority of events took place outside the village (32 in 2010 and 71 events in 2011) and many took place beyond $10 \mathrm{~km}$ (6 in 2010, 34 events in 2011). Up to $25 \%$ of seed acquisition events were engaged with individuals living further than $8.6 \mathrm{~km}$ away. Thus, a considerable expansion of the geographical area of seed acquisitions occurred during the bad year: the median distance of seed acquisitions rose from 1.7 $\mathrm{km}$ to $3.1 \mathrm{~km}$.
Fig. 5. Geographical extent of the network: a) in 2010 and b) in 2011. The red triangle represents the study site. The first quartile (in blue) indicates that $25 \%$ of the seed acquisitions occurred within this radius. The red median delimits the area within which $50 \%$ of the seed acquisitions took place, and the third quartile (in green) corresponds to the distance within which $75 \%$ of seed acquisitions unfolded. The point size represents the number of seed acquisition events at this location.

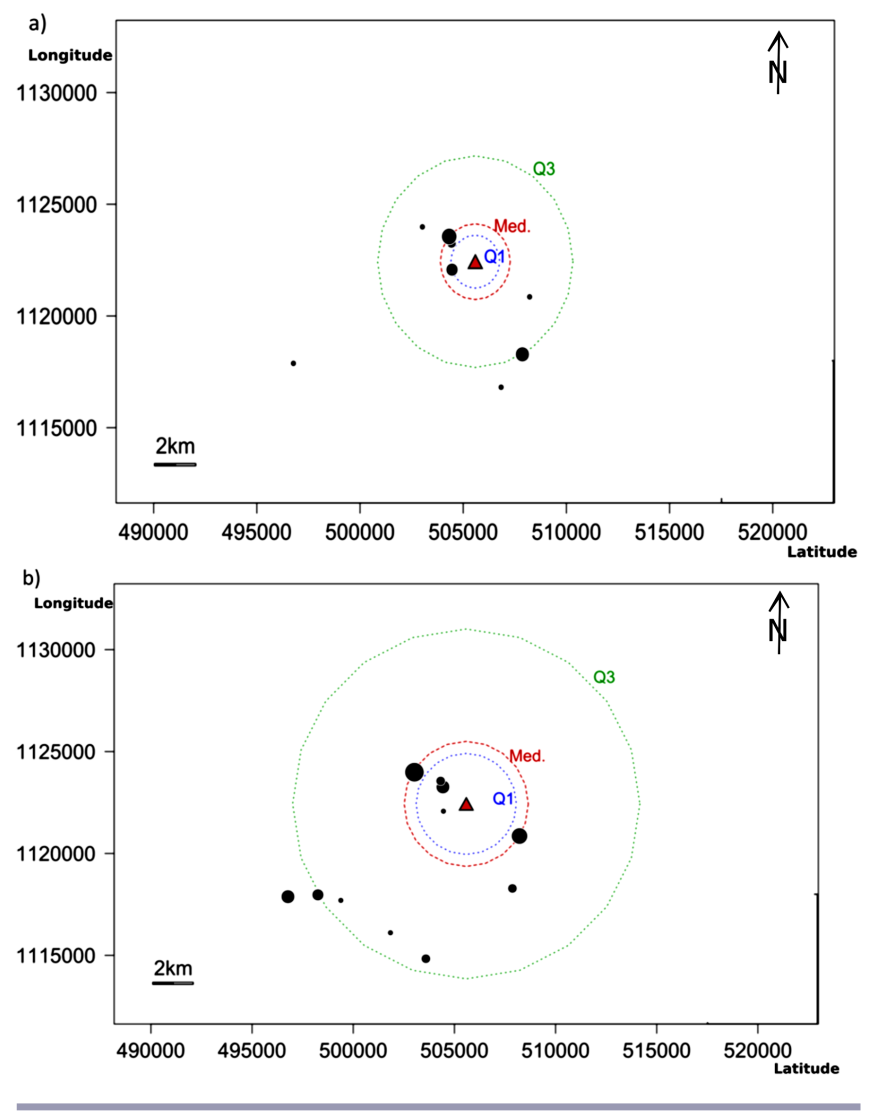

This extension was the direct result of the search for cereal seeds. Of the 71 events that occurred outside the village in the second year, $44 \%$ concerned cereals: 12 events for red sorghum, 11 for pearl millet, 5 for transplanted sorghum, 2 for maize, and 1 for rice. Some secondary crops were also acquired at similar distances: 7 events for sorrel, 6 for okra, and 4 for calabash.

The geographical expansion of the network during a difficult farming season is paradoxically paralleled by the fact that the most stable partners from one year to the other were the closest ones, geographically speaking. When we examined the events that were repeated from one year to the other involving the exact same pair or partners, the network was very restricted (Fig. 6). We identified only 40 repeated transaction relationships (13.1\% of all acquisitions) linking 21 households. The network concerned firstly members from the same household (18 events corresponding to the loops), i.e., husbands and wives, or mothers and sons. The 22 remaining interhousehold events were mainly between very close neighbors (in orange on the figure) or mothers and their daughters (in green). 
Fig. 6. The network of repeated transactions from 2010 to 2011. The green nodes represent the interviewed seed recipients and the blue ones are the providers. The colors of the edges distinguish seed acquisitions between members of the same household (loops), neighbors (in orange), mothers and their daughters (in green), and other partners (in grey). The width of an edge represents the number of seed acquisition events (ranging from 1 to 6 ).

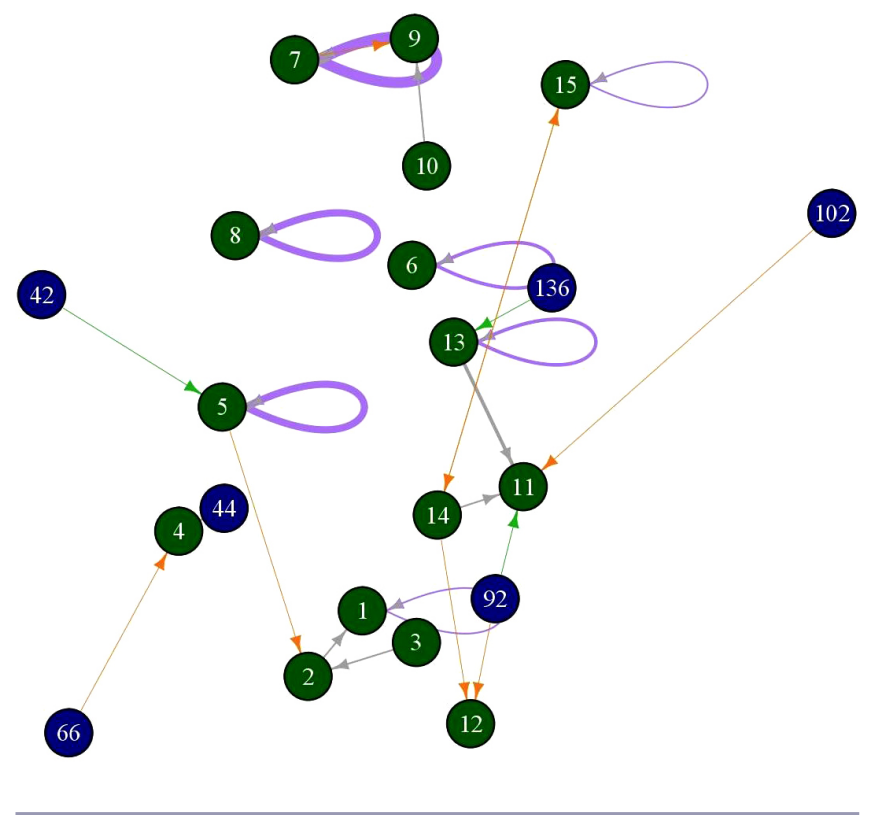

However, the geographical expansion, combined with the limited number of repeated transactions from year to year, does not necessarily indicate that the structure of farmers' social networks completely changed. A key finding of our study is that farmers tended to acquire seeds not always from the same person, but from the same categories of partners. This was particularly true for acquisitions from neighbors within the village, which were frequent whatever the year (15\% of acquisitions in 2010 and $26 \%$ in 2011). However, although farmers often relied locally on their family and neighbors, what categories of partners did they seek for seed provisioning of major crops during a difficult farming season?

\section{Women's significant contribution to seed acquisition networks}

\section{Women as main actors}

Women were essential actors in seed transactions during the bad year $(p=0.003$; Table1). These results are consistent with those of the MCA (Fig. 4). When Figures 4a, 4f, and 4b are compared, events that are observed in the upper part of the plots are those that occurred mostly during the bad year (in red in Fig. 4a), outside the village (in green in Figure 4f), and involving mostly women as recipients (in blue in Fig. 4b).

Women were furthermore substantially more frequently involved in long-distance acquisitions in 2011 compared with 2010. Up to $72 \%$ of the total acquisitions were made by women in 2011 , and they were also active as providers. In fact, whatever the year, women frequently sought to give seeds; 70 of the providers were female and 58 were male in 2010; 132 of the providers were female and 45 were male in 2011. In 2011, women were also the most active as long-distance seed seekers $(69 \%$ of the outside village acquisitions were made by women), even though they had not been the main actors in acquisitions in 2010. Specifically, they managed to access the crucial pearl millet seeds: 15 of the 21 pearl millet acquisitions were made by women. Who were the distant seed providers that women sought out during the critical year?

\section{Partnerships with in-laws and uterines}

The main categories of social relations through which seed transactions occurred were not significantly different between the two years $(\mathrm{p}=0.095$; Table 1$)$. Nevertheless, and consistent with ethnographical observations, results of the MCA (Fig. 4h) showed that some types of partners were more regularly sought out in the second year. Comparison of Figures $4 \mathrm{a}$ and $4 \mathrm{~h}$ reveals that events during the bad year, which are mostly in the upper part of the plot (in red in Figure 4a), are also those that occurred through uterines and strangers (in light grey and black in Figure 4h). Indeed, farmers relied heavily on uterine relationships, which represented $20 \%$ of all events in 2011 (14 in 2010 vs. 35 in 2011). Another social relationship stood out as particularly frequently mobilized in seed exchanges in 2011: the relationship with in-laws from within the village (Table 3). In-laws were mobilized twice as often in 2011 ( 57 events) as in 2010 (24 events), making them the most frequent partners for seed acquisitions in the 2011 cropping season. Because transactions involving in-laws mainly occurred within less than $1 \mathrm{~km}$, they particularly concerned in-laws from the community. In contrast to the unexpected increase in frequency of these three categories of partners, other relationships were mobilized in almost equivalent proportions in the two years (e.g., neighbors, acquaintances and friends); they were more regular seed sources.

This tendency to rely on the same relational category led us to detect the existence of a common social structure underlying the seed networks for the two cropping seasons. Although the network edges may be similarly characterized in terms of categories of social relationship, it is important to bear in mind that each acquisition act remains singular.

\section{A matter of quantity}

Networks of the two cropping seasons presented several differences in terms of seed flows, especially when quantities of acquired seeds were considered. Pooling all events in 2011, it appears that providers, on average, gave smaller quantities of seeding material (events in blue in Fig. 4e that correspond to events in red in the bad year, Fig. 4a). Nevertheless, these differences in the amount of acquired germplasm were not statistically significant $(p=0.304$; Table 1$)$. This trend is surprising given that our first assessment indicated an overall larger quantity of acquired material in 2011 (280 cups in 2010 vs. 411 cups in 2011). The apparent discrepancy results from the fact that, in 2011, transactions included a small number that involved very large quantities, i.e., more than 10 cups.

Furthermore, we noted differences in behavioral patterns between regular and emergency partners. In-laws and uterines were the two social categories that provided larger quantities in 2011 than in 2010 (Fig. 7). Although in-laws provided seeds more frequently (a greater number of transactions) in 2011, they provided seeds 
Table 3. Proportion of seed acquisition events according to the type of relationship and distance between providers and recipients in 2010 and 2011.

\begin{tabular}{|c|c|c|c|c|c|c|c|}
\hline & & \multicolumn{6}{|c|}{ Geographical distances } \\
\hline & & $<1 \mathrm{~km}$ & $1-3 \mathrm{~km}$ & $3-5 \mathrm{~km}$ & $5-10 \mathrm{~km}$ & $>10 \mathrm{~km}$ & Total \\
\hline \multicolumn{8}{|c|}{2010} \\
\hline & Neighbor & 23.44 & 1.56 & 0.00 & 0.00 & 0.78 & 25.78 \\
\hline & In-law & 21.88 & 0.78 & 0.00 & 0.00 & 0.00 & 22.66 \\
\hline & Agnate & 12.50 & 0.00 & 0.00 & 0.78 & 1.56 & 14.84 \\
\hline & Friend & 9.38 & 3.13 & 1.56 & 0.00 & 0.00 & 14.06 \\
\hline & Uterine & 5.47 & 0.00 & 2.34 & 2.34 & 0.78 & 10.94 \\
\hline & Acquaintance & 1.56 & 3.91 & 3.13 & 0.00 & 0.78 & 9.38 \\
\hline & Stranger & 0.00 & 0.00 & 0.00 & 0.78 & 0.78 & 1.56 \\
\hline & Other & 0.00 & 0.78 & 0.00 & 0.00 & 0.00 & 0.78 \\
\hline & Total & 74.22 & 10.16 & 7.03 & 3.91 & 4.69 & 100.00 \\
\hline \multicolumn{8}{|c|}{2011} \\
\hline & In-law & 29.38 & 2.82 & 0.00 & 0.00 & 0.00 & 32.20 \\
\hline & Uterine & 7.34 & 0.56 & 1.13 & 1.69 & 9.04 & 19.77 \\
\hline & Neighbor & 11.86 & 2.82 & 0.56 & 0.00 & 0.00 & 15.25 \\
\hline & Friend & 2.82 & 2.26 & 2.26 & 0.56 & 1.69 & 9.60 \\
\hline & Acquaintance & 0.56 & 3.39 & 2.26 & 0.56 & 1.69 & 8.47 \\
\hline & Stranger & 1.13 & 0.00 & 1.13 & 0.56 & 5.08 & 7.91 \\
\hline & Agnate & 2.82 & 0.56 & 1.13 & 0.56 & 1.69 & 6.78 \\
\hline & Other & 0.00 & 0.00 & 0.00 & 0.00 & 0.00 & 0.00 \\
\hline & Total & 55.93 & 12.43 & 8.47 & 3.95 & 19.21 & 100.00 \\
\hline
\end{tabular}

Fig. 7. Distribution of acquired seed quantities over the two seasons: a) in the whole sample, b) for partners that are in-laws, and c) for uterines.
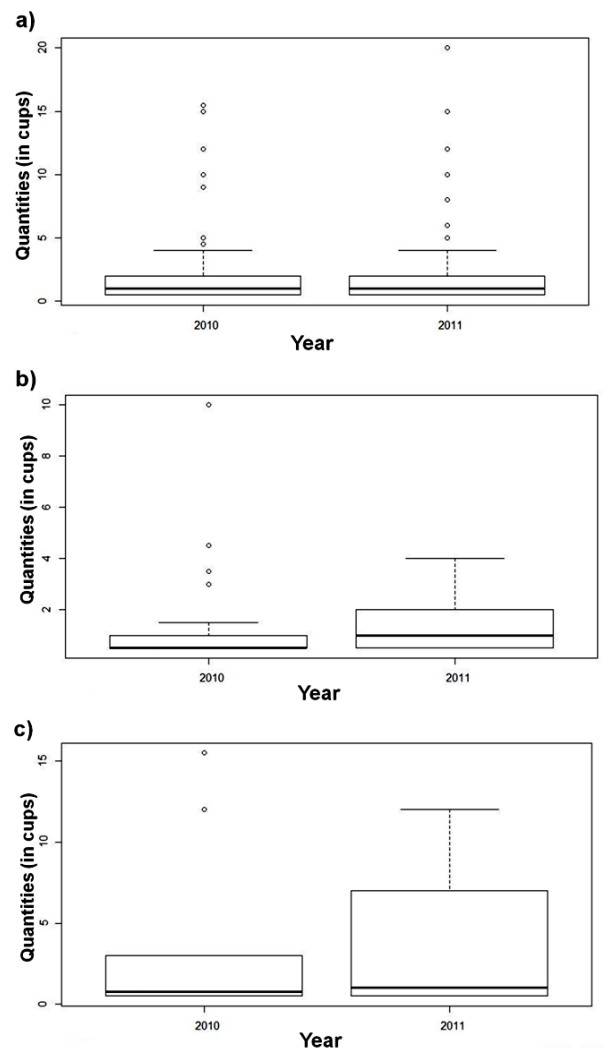

in smaller quantities per transaction (two acquisitions involving more than 2 cups) than the uterines, the biggest providers during the second year (10 acquisitions involving more than 2 cups).

\section{Inequalities in farmers' seed networks}

The ways in which seeds were acquired during the good year and the bad year did not seem to vary as a function of the economic status of the household ( $p=0.104$; Table 1$)$. However, according to the MCA results (Fig. 4c), members of rich and intermediate households seemed to be engaged in more seed transactions in 2011, whereas in the same time members of poor households were surprisingly less active in acquisitions. Differences in households' strategies in coping with rainfall uncertainty were also evident when we considered the relationships that were preferentially sought out to acquire seeds. Members of rich and intermediate families were those who mobilized their uterine and in-law partners to a greater extent the second year (Table 4), whereas members of the poorest households did not succeed in acquiring more seeds through their uterine ties and actually relied on their geographically nearest partners, i.e., in-laws and neighbors from their village.

\section{DISCUSSION}

Cereal substitution and resilience of the network

The climatic shocks that Tupuri farmers faced in 2011 (i.e., late beginning of rains) did not lead to a dramatic change in their strategies in terms of crop choice and seed acquisitions. Even though the staple crops were the most likely to be threatened, farmers did not focus particularly on acquiring seeds of major crops. Farmers reacted to the shock in a subtle way (Ember 2013). First, they strove to maintain diversity of crop species, acquiring a somewhat more frequently seeds of secondary crops the second year. Maintaining or even enhancing the diversity of species 
Table 4. Seed acquisition events according to household economic status and social relationships for 2010 and 2011.

\begin{tabular}{llccc}
\hline \hline & & 2010 & 2011 & Total \\
\hline Poor households & & 38 & 35 & 73 \\
& In-law & 9 & 13 & 22 \\
& Neighbor & 13 & 6 & 19 \\
& Friend & 3 & 5 & 8 \\
& Acquaintance & 4 & 4 & 8 \\
& Agnate & 4 & 3 & 7 \\
& Uterine & 5 & 3 & 8 \\
& Stranger & 0 & 1 & 1 \\
Intermediate households & 45 & 78 & 123 \\
& In-law & 11 & 26 & 37 \\
& Uterine & 5 & 14 & 19 \\
& Neighbor & 8 & 14 & 22 \\
& Stranger & 1 & 11 & 12 \\
& Friend & 10 & 6 & 16 \\
& Acquaintance & 5 & 5 & 10 \\
& Agnate & 5 & 2 & 7 \\
Rich households & 45 & 64 & 109 \\
& In-law & 9 & 18 & 27 \\
& Uterine & 4 & 18 & 22 \\
& Agnate & 10 & 7 & 17 \\
& Neighbor & 12 & 7 & 19 \\
& Friend & 5 & 6 & 11 \\
& Acquaintance & 3 & 6 & 9 \\
& Stranger & 1 & 2 & 3 \\
& Other & 1 & 0 & 1 \\
& & 128 & 177 & 305 \\
\hline \multirow{5}{*}{ Total } & & &
\end{tabular}

appears to be a frequent and effective strategy for coping with climatic hazards (Fischer et al. 2006, Duru et al. 2015, Glamann et al. 2015). Second, changes in the farmer's portfolio of landraces was also important, especially within the category of cereals.

In fact, because red sorghum is vulnerable to rainfall shortage, in 2011 farmers switched to pearl millet, which can be sown up to a month later. Nevertheless, acquisitions of seed of red sorghum remained frequent in 2011 for two reasons. First, because it is the first plant sown, farmers prepare seed lots at the very beginning of the season to have enough stock on hand when the time for sowing comes. At the time when they seek seeds, they cannot predict whether rains will start late. Second, although most farmers waited for the heaviest rains to sow, some farmers decided to sow their seeds too quickly. Having lost their first seed lot because of failure of the rains, those farmers wished to acquire seeds of red sorghum, as well as those of plants intercropped with it, such as okra, sorrel, or calabash, to prepare for a second sowing.

When the onset of the rainy season comes late, as in 2011, sowing exclusively red sorghum as the major cereal is risky. The main strategy to cope with an unexpectedly late beginning of the rainy season is to adjust the crop portfolio and seek to diversify the length of the cycles of various species and landraces (Raimond 1999). That is why, in 2011, when farmers realized that the latecoming rains would make a second sowing of red sorghum impossible, they decided to switch to pearl millet, which is a more drought-resistant and faster maturing crop than sorghum. The yield of pearl millet would be satisfactory even during a shortened rainy season. Because in normal times only a few panicles of pearl millet are grown within the red sorghum fields, in 2011 farmers had an urgent need for larger quantities of pearl millet seeds to grow on larger plots. This emergency demand had an effect on both the categories of partners sought out for the necessary acquisitions and the quantities required.

\section{Going the distance in difficult times: stable versus emergency partners}

A significant geographic expansion of the network beyond the village was noted during the climatically critical year. Looking for cereal seeds further away is necessary because farmers from the same village tend to adopt similar strategies, leading to a local shortage in the supply of desired seeds (Zimmerer 2003). The lack of locally available pearl millet seeds led farmers to target people living outside their community. The year 2011 was a bad year all across the region; however, farmers in some villages within the range within which seeds could be acquired habitually sow more pearl millet compared with other villages because they have larger areas of sandy soils suited to this drought-resistant species. Consequently, farmers seeking seeds looked for people among their acquaintances who had larger quantities of millet seeds. They also turned toward relatives in distant villages. Even if these relatives experienced similar difficulties, they could not refuse these requests because of the relation linking them. This consideration may explain why we occasionally observed that when a relative from a distant village came to the focal village seeking seeds, their kin in the village also had to give seeds, despite the fact that they had no more seeds than the seekers. Going the distance to seek such cereal seeds also provided occasions for acquiring seeds of secondary crops. Our ethnographic observations reveal that even though acquiring seeds of secondary crops was not the main objective of their travels, farmers acquired such seeds either as supplementary gifts or opportunistically when they spotted interesting seeds. Diversity of crops is seen by Tupuri farmers as a way to cope with unpredictable rainfall.

The contingent geographical expansion of the network did not lead to a complete change in the network structure. If distant partners were sought out more often because of the late rains, such partners could be considered as latent resources in other years. In other words, they are regularly present in seed acquisitions although they are particularly solicited in emergency situations (Coomes et al. 2015). The mother-daughter relationship is illustrative, because it is one of the few relationships mobilized in both years and because many of the cereal acquisitions of 2011 were channeled through this tie. Because of the patrilocal system, mothers and daughters can live in distant locations. In contrast, neighbors were not more frequently sought out in times of distress, but they represent a constant and basic source for all daily life exchanges (McGuire 2008).

The rare cases where farmers returned to the same source of seeds from one year to the next go against a Tupuri cultural norm. Requesting seeds on a regular basis from the same individual is morally reproved and shameful (shame: söorè in Tupuri), and as such is avoided as much as possible. Similar observations have been made in other African contexts (Labeyrie 2013, Samberg et al. 2013). A deviation from such cultural norms is only tolerated within these relations of geographical and social proximity. However, even if farmers avoid acquiring seeds from the same persons through time, they rely on the same relational categories 
of people. Each farmer has a stock of potential partners that he/ she can mobilize in different ways according to the specific needs he/she encounters from year to year. Having this reliable stock of partners enhances, once again, the farmers' adaptive capacity in the face of unexpected environmental conditions (Mortimore and Adams 2001, Roncoli 2006, Nielsen and Reenberg 2010).

\section{Women as agents for resilience}

The crucial role of women in seed supplies for cereals is a surprising finding given that, in local discourse, cereals fall into men's domain. Red sorghum seeds, for instance, are labeled by people of the region as "the seeds of our fathers" (Wencélius and Garine 2014). Women, however, are the only ones to take care of seed conservation in granaries and are the main actors in selection of seeds for sowing. Our case study reveals that women are also responsible for responding in emergency situations. In 2011, they proved to be the main acquirers of pearl millet seeds, which was a key asset for successful adaptation to the late rains.

Sometimes autonomously, sometimes at the request of their husbands, they traveled across the Tupuri region to rapidly access seeds. They did not rely on their husband's network but rather solicited members of their own kin group, in particular their uterine relations. That is why kinship tends to be over-represented in the relationships mobilized when emergencies arise. Uterine partners are more easily mobilized by these women than other kinds of relations because of a virtuous cycle of social and moral obligations. According to the rule of patrilocal residence, uterines live outside the village; they are the mothers, aunts, or grandmothers of our women interviewees. Close kin cannot refuse to provide seed to their own "daughter" who has traveled a long distance to seek seeds, nor let them go with small quantities even when they themselves lack large quantities of grain. Moral norms and social rules compel people to give more to kinsmen coming from distant villages, even if such prodigality implies having to seek small quantities locally to replace the substantial quantities given away. Such small, local acquisitions are often carried out between women and their in-laws living in the same village (e.g., their husband's mother or their husband's brothers' spouses). Because farmers rarely go far away to seek seeds (and when they do so, it usually involves an emergency, as in 2011), they can obtain larger quantities by exchange with their matrilineal kin than through regularly solicited partners (Delêtre et al. 2011).

\section{Social inequalities in facing climatic shocks}

Although no statistically significant inequalities appeared in seed provisioning during the bad year, ethnographical observations suggest that the economic status of households nonetheless affects the nature of the channels through which seeds can be acquired (Wencélius et al. 2016). The distribution of seed acquisition events across the main categories of social relationships over the two cropping seasons indicates that all farmers do not have the same ability to mobilize these emergency partners and to cope with climate unpredictability (Louette et al. 1997, McGuire 2008). This result is supported by our ethnographic fieldwork, during which we observed that farmers belonging to households of the intermediate wealth stratum (generally young couples) were often those who were the most assisted. As beginners in agriculture, they have the most moral legitimacy as farmers who can ask for seeds, especially in difficult periods.
Members of rich households also have material and social resources to cope with uncertainty (Poudel et al. 2015). They are sometimes prominent figures (local government officials, customary chiefs or retired "elites" from urban centers) within the village, and they also have numerous ties outside the village (Granovetter 1983). However, they are not nodal farmers, even in bad years. In 2011, they sought out as many seeds as the other households and were not the principal providers to the less wealthy households. This is partly because of the rule that restricts people from asking the same person over and over again, and also because of the individual management of seed stock. Even in the wealthy families, women and adolescents need to seek their seeds independently.

The poorest households were not engaged in distinct seed acquisitions strategies in terms of events, quantities, and crop categories, but they had greater difficulties in attempting to mobilize the key relationships. Whatever the year, they had to rely more on their neighbors as seed sources, with all the constraints that this implies (smaller quantities and a greater proportion of refusals). In a bad year, as in 2011, they were not able to find more seeds with their uterines, as the others did. As our ethnographical observations suggested, shame prevented these farmers, who were old widows in the majority of cases, from begging for seeds. Although the age effect was not tested here, other studies on societies in the same region have shown that elders are reluctant to ask for seeds from younger farmers (Alvarez et al. 2005). Despite the general trend to readjust the varietal cereal portfolio and to seek seeds further and with more reliable partners, all the households are unlikely to implement exactly the same strategies. The household's socioeconomic status has an impact on the possible channels through which it can acquire seeds.

\section{CONCLUSION}

Even the most detailed study of farmer-to-farmer seed transactions can only provide a glimpse of individuals' actual social network. Because of the moral rule according to which "begging" seeds from the same partners in two consecutive years is socially penalized (Samberg et al. 2013), analyzing seed acquisition networks in two "normal" years would probably have revealed the same absence of stable and repeated partnerships. However, studying the patterns of seed acquisitions through successive cropping seasons characterized by different environmental constraints is instructive, providing information on how farmers may differentially mobilize their social network to adapt their farming strategies to unpredictable climatic variations.

In the light of farmers' ability to react to a substantial delay in the onset of the rainy season and their overall ability to meet production requirements in such unfavorable conditions, changes in the observed network patterns should not be regarded as manifestations of social or agricultural crises but rather as expressions of adaptive capacity. When bad things happen, such as lack of rainfall at the crucial moment, farmers never find themselves without strategies of action: They are used to adjusting their farming choices. Even if this research does not allow us to draw definitive conclusions as to the success of the readjustments made, it nevertheless shows how quickly and effectively farmers can react to these disruptions by using their social network. 
In terms of network dynamics, it appears that some components of the network are idle and are triggered by farmers only when they encounter particularly constraining conditions. This latent network structure is largely conditioned by rules of social organization (rules of marriage, residence, and descent), and each of its potential relationships is governed by a specific set of moral obligations, social duties, and expected behaviors. An ethnographically informed description of these obligations, duties, and behaviors is fundamental to understand which relationships are preferred to acquire seeds under varying economic and ecological conditions, enabling us to shed light on the varying expressions, from year to year, of a relatively stable structure in the local seed system.

Longitudinal studies of seed acquisition behaviors are crucial for research seeking to identify the impacts of both short-term climatic variation and chronic unpredictability on configurations of farmer-to-farmer networks. Such studies would also enable us to reconsider farmers' agency in the forging and structuring of social networks and to avoid the reification of social networks as long-lasting structures in which individuals navigate. In fact, seed transaction networks are only the emergent properties of actors' behavior in seed provisioning.

Responses to this article can be read online at: http://www.ecologyandsociety.org/issues/responses. $\mathrm{php} / 8376$

\begin{abstract}
Acknowledgments:
The authors gratefully acknowledge the French Fondation pour la Recherche sur la Biodiversité (FRB) that made possible NetSeed, an international collaboration of researchers studying farmer seed networks. The Centre de Synthèse et d'Analyse sur la Biodiversité (CESAB) provided essential logistical support for regular workshops on the subject that enabled us to develop and mature both the theoretical and methodological aspects of our research. Additional support of the ongoing research collaboration through the MIRES and MADRES networks was provided by the following agencies: the Réseau National des Systèmes Complexes (RNSC), the Institut National de la Recherche Agronomique (INRA), and the Centre National de la Recherche Scientifique (CNRS). We are most thankful for the patience and time of farmers from Lokoro and Gulurgu, who generously offered to answer our questions and to share their daily experiences. This work would not have been possible without the constant help from Ngomna Gaygue, Etienne Houinwe, and Mosono Wedjo, our research assistants in the field. Finally, we thank Doyle McKey and Jean Wencélius for their help in editing our final manuscript.
\end{abstract}

\section{LITERATURE CITED}

Abay, F., W. de Boef, and Å. Bjørnstad. 2011. Network analysis of barley seed flows in Tigray, Ethiopia: supporting the design of strategies that contribute to on-farm management of plant genetic resources. Plant Genetic Resources 9(4):495-505. http://dx.doi. org/10.1017/s1479262111000773

Alvarez, N., E. Garine, C. Khasah, E. Dounias, M. HossaertMcKey, and D. McKey. 2005. Farmers' practices, metapopulation dynamics, and conservation of agricultural biodiversity on-farm: a case study of sorghum among the Duupa in sub-Sahelian Cameroon. Biological Conservation 121(4):533-543. http://dx.doi. org/10.1016/j.biocon.2004.05.021

Atran, S., D. Medin, N. Ross, E. Lynch, V. Vapnarsky, E. Ucan Ek', J. Coley, C. Timura, and M. Baran. 2002. Folkecology, cultural epidemiology, and the spirits of the commons: a garden experiment in the Maya lowlands, 1991-2001. Current Anthropology 43(3):421-450. http://dx.doi.org/10.1086/339528

Badstue, L. B., M. R. Bellon, J. Berthaud, X. Juárez, I. M. Rosas, A. M. Solano, and A. Ramírez. 2006. Examining the role of collective action in an informal seed system: a case study from the central valleys of Oaxaca, Mexico. Human Ecology 34(2):249-273. http://dx.doi.org/10.1007/s10745-006-9016-2

Bellon, M. R., D. Hodson, and J. Hellin. 2011. Assessing the vulnerability of traditional maize seed systems in Mexico to climate change. Proceedings of the National Academy of Sciences of the United States of America 108(33):13432-13437. http://dx. doi.org/10.1073/pnas.1103373108

Calvet-Mir, L., M. Calvet-Mir, J. Luis Molina, and V. ReyesGarcía. 2012. Seed exchange as an agrobiodiversity conservation mechanism. A case study in Vall Fosca, Catalan Pyrenees, Iberian Peninsula. Ecology and Society 17(1):29. http://dx.doi. org/10.5751/ES-04682-170129

Coomes, O. T, S. McGuire, E. Garine, S. Caillon, D. McKey, E. Demeulenaere, D. Jarvis, G. Aistara, A. Barnaud, P. Clouvel, L. Emperaire, S. Louafi, P. Martin, F. Massol, M. Pautasso, C. Violon, and J. Wencélius. 2015. Farmer seed networks make a limited contribution to agriculture? Four common misconceptions. Food Policy 56:41-50. http://dx.doi.org/10.1016/j.foodpol.2015.07.008

Crane, T. A., C. Roncoli, and G. Hoogenboom. 2011. Adaptation to climate change and climate variability: the importance of understanding agriculture as performance. NJAS - Wageningen Journal of Life Sciences 57(3-4):179-185. http://dx.doi. org/10.1016/j.njas.2010.11.002

Csardi, G., and T. Nepusz. 2006. The igraph software package for complex network research. InterJournal Complex Systems 1695 (5):1-9. [online] URL: http://www.necsi.edu/events/iccs6/papers/ c1602a3c126ba822d0bc4293371c.pdf

Delêtre, M., D. B. McKey, and T. R. Hodkinson. 2011. Marriage exchanges, seed exchanges, and the dynamics of manioc diversity. Proceedings of the National Academy of Sciences of the United States of America 108(45):18249-18254. http://dx.doi.org/10.1073/ pnas. 1106259108

Dray, S., and A.-B. Dufour. 2007. The ade4 package: implementing the duality diagram for ecologists. Journal of Statistical Software 22(4):1-20. [online] URL: http://pbil.univlyon1.fr/ade4/article/jss/jss.pdf

Duru, M., O. Therond, G. Martin, R. Martin-Clouaire, M.-A. Magne, E. Justes, E.-P. Journet, J.-N. Aubertot, S. Savary, J.-E. Bergez, and J.-P. Sarthou. 2015. How to implement biodiversitybased agriculture to enhance ecosystem services: a review. Agronomy for Sustainable Development 35(4):1259-1281.http:// dx.doi.org/10.1007/s13593-015-0306-1 http://dx.doi.org/10.1007/ s13593-015-0306-1 
Eldin, M., and P. Milleville, editors. 1989. Le risque en agriculture. ORSTOM, Paris, France. [online] URL: http://horizon. documentation.ird.fr/exl-doc/pleins textes/divers07/27222.pdf

Ember, C. R. 2013. Introduction to "coping with environmental risk and uncertainty: individual and cultural responses." Human Nature 24(1):1-4. http://dx.doi.org/10.1007/s12110-013-9161-4

Fischer, J., D. B. Lindenmayer, and A. D. Manning. 2006. Biodiversity, ecosystem function, and resilience: ten guiding principles for commodity production landscapes. Frontiers in Ecology and the Environment 4(2):80-86. http://dx.doi. org/10.1890/1540-9295(2006)004[0080:BEFART]2.0.CO;2

Garine, E., A. Luxereau, J. Wencélius, C. Violon, T. Robert, A. Barnaud, S. Caillon, and C. Raimond. 2013. De qui les variétés traditionnelles de plantes cultivées pourraient-elles être le patrimoine? Réflexions depuis le bassin du lac Tchad. Pages 379-409 in D. Juhé-Beaulaton, M.-C. Cormier-Salem, P. D. Robert, and B. Roussel, editors. Effervescence patrimoniale au Sud: entre nature et société. IRD, Marseille, France.

Glamann, J., J. Hanspach, D. J. Abson, N. Collier, and J. Fischer. 2015. The intersection of food security and biodiversity conservation: a review. Regional Environmental Change:1-11. http://dx.doi.org/10.1007/s10113-015-0873-3

Granovetter, M. S. 1983. The strength of weak ties: a network theory revisited. Sociological Theory 1(6):201-233. http://dx.doi. org/10.2307/202051

Isaac, M. E., B. H. Erickson, S. Quashie-Sam, and V. R. Timmer. 2007. Transfer of knowledge on agroforestry management practices: the structure of farmer advice networks. Ecology and Society 12(2):32. [online] URL: http://www.ecologyandsociety. org/vol12/iss $2 / \operatorname{art} 32 /$

Kawa, N. C., C. McCarty, and C. R. Clement. 2013. Manioc varietal diversity, social networks, and distribution constraints in rural Amazonia. Current Anthropology 54(6):764-770. http://dx. doi.org/10.1086/673528

Kolyang, T. 2010. Parlons tpuri: [Cameroun et Tchad]. Harmattan, Paris, France.

Labeyrie, V. 2013. L'organisation sociale des plantes cultivées. Influence des échanges, représentations et pratiques sur la diversité du sorgho (Sorghum bicolor [L.] Moench) chez les peuples $d u$ mont Kenya. Dissertation. Université de Montpellier/SupAgro, Montpellier, France.

Leclerc, C., and G. Coppens d'Eeckenbrugge. 2012. Social organization of crop genetic diversity. The $\mathrm{G} \times \mathrm{E} \times \mathrm{S}$ interaction model. Diversity 4(1):1-32. http://dx.doi.org/10.3390/d4010001

Louette, D., A. Charrier, and J. Berthaud. 1997. In situ conservation of maize in Mexico: genetic diversity and maize seed management in a traditional community. Economic Botany 51 (1):20-38. http://dx.doi.org/10.1007/bf02910401

McGuire, S. J. 2008. Securing access to seed: social relations and sorghum seed exchange in eastern Ethiopia. Human Ecology 36 (2):217-229. http://dx.doi.org/10.1007/s10745-007-9143-4

McGuire, S., and L. Sperling. 2013. Making seed systems more resilient to stress. Global Environmental Change 23(3):644-653. http://dx.doi.org/10.1016/j.gloenvcha.2013.02.001
Mortimore, M. J., and W. M. Adams. 2001. Farmer adaptation, change and 'crisis' in the Sahel. Global Environmental Change 11 (1):49-57. http://dx.doi.org/10.1016/S0959-3780(00)00044-3

Nielsen, J. Ø., and A. Reenberg. 2010. Temporality and the problem with singling out climate as a current driver of change in a small West African village. Journal of Arid Environments 74 (4):464-474. http://dx.doi.org/10.1016/j.jaridenv.2009.09.019

Pautasso, M., G. Aistara, A. Barnaud, S. Caillon, P. Clouvel, O. T. Coomes, M. Delêtre, E. Demeulenaere, P. de Santis, T. Döring, L. Eloy, L. Emperaire, E. Garine, I. Goldringer, D. Jarvis, H. I. Joly, C. Leclerc, S. Louafi, P. Martin, F. Massol, S. McGuire, D. McKey, C. Padoch, C. Soler, M. Thomas, and S. Tramontini. 2013. Seed exchange networks for agrobiodiversity conservation. A review. Agronomy for Sustainable Development 33(1):151-175. http://dx.doi.org/10.1007/s13593-012-0089-6

Poudel, D., B. Sthapit, and P. Shrestha. 2015. An analysis of social seed network and its contribution to on-farm conservation of crop genetic diversity in Nepal. International Journal of Biodiversity 2015:312621. http://dx.doi.org/10.1155/2015/312621

R Development Core Core Team. 2014. R: a language and environment for statistical computing. $\mathrm{R}$ foundation for Statistical Computing, Vienna, Austria. [online] URL: http://www.Rproject.org/

Raimond, C. 1999. Terres inondées et sorgho repiqué: évolution des espaces agricoles et pastoraux dans le bassin du lac Tchad. Dissertation. Université Paris 1: Panthéon-Sorbonne, Paris, France.

Reyes-García, V., J. L. Molina, L. Calvet-Mir, L. Aceituno-Mata, J. J. Lastra, R. Ontillera, M. Parada, M. Pardo-de-Santayana, M. Rigat, J. Vallès, and T. Garnatje. 2013. "Tertius gaudens": germplasm exchange networks and agroecological knowledge among home gardeners in the Iberian Peninsula. Journal of Ethnobiology and Ethnomedicine 9(1):53-62. http://dx.doi. org/10.1186/1746-4269-9-53

Roncoli, C. 2006. Ethnographic and participatory approaches to research on farmers' responses to climate predictions. Climate Research 33(1):81-99. http://dx.doi.org/10.3354/cr033081

Ruelland, S. 1983. Dis-moi, qui sont tes fils? Analyse sémantique de la parenté et de l'alliance tupuri. Pages 89-108 in Théories et pratiques linguistiques. Société pour l'Information Grammaticale, Paris, France.

Samberg, L. H., C. Shennan, and E. Zavaleta. 2013. Farmer seed exchange and crop diversity in a changing agricultural landscape in the Southern Highlands of Ethiopia. Human Ecology 41 (3):477-485. http://dx.doi.org/10.1007/s10745-013-9579-7

Seignobos, C. 2000. Sorghos et civilisations agraires. Planche 14 in C. Seignobos and O. Iyébi-Mandjek, editors. Atlas de la province Extrême-Nord Cameroun. IRD, Paris, France.

Tenenhaus, M., and F. W. Young. 1985. An analysis and synthesis of multiple correspondence analysis, optimal scaling, dual scaling, homogeneity analysis and other methods for quantifying categorical multivariate data. Psychometrika 50(1):91-119. http:// dx.doi.org/10.1007/BF02294151 
Violon, C., and J. Wencélius. 2014. Les échanges monétaires en zone rurale dans le Mayo-Danay (Extrême-Nord du Cameroun): lieux, acteurs et pratiques. Pages 197-219 in S. Baldi and G. Magrin, editors. Les échanges et la communication dans le bassin du lac Tchad (Actes du 15ème colloque du réseau Méga-Tchad). 13-15 septembre. L'Orientale, Naples, Italie.

Wencélius, J., and É. Garine. 2014. Dans les sillons de l'alliance. Ethnographie de la circulation des semences de sorgho dans l'extrême-Nord du Cameroun. Cahiers d'Outre-Mer 265:93-116. http://dx.doi.org/10.4000/com.7082

Wencélius, J., T. Thomas, P. Barbillon, and E. Garine. 2016. Interhousehold variability and its effects on seed circulation networks: a case study from northern Cameroon. Ecology and Society, in press.

Zimmerer, K. S. 2003. Geographies of seed networks for food plants (potato, ulluco) and approaches to agrobiodiversity conservation in the Andean countries. Society \& Natural Resources 16(7):583-601. http://dx.doi.org/10.1080/08941920309185 